\title{
Motivos hegelianos en la concepción del trabajo del Joven Marx
}

\author{
Hegelian Motives in Young Marx's Conception of Labor \\ Motivos hegelianos na concepção do trabalho do jovem Marx
}

Alexis Emanuel Gros ${ }^{1}$

Resumen

Con el objetivo de superar las lecturas literales e irreflexivas de los Manuscritos económico-filosóficos de 1844, el presente escrito se propone identificar los motivos hegelianos que informan la concepción del trabajo esgrimida por el joven Marx. Para ello, en primer lugar, se reconstruye el abordaje del problema del trabajo que Hegel lleva a cabo en la Fenomenología del espíritu. Y, en segundo término, se realiza una lectura a contrapelo del manuscrito sobre "el trabajo alienado", orientada a revelar la concepción positiva del trabajo de Marx y a mostrar los motivos hegelianos que la influyen.

Palabras clave: Joven Marx, trabajo, alienación, Hegel, Marxismo.

\section{Abstract}

With the aim of overcoming the literal and thoughtless readings of the Economic and Philosophic Manuscripts of 1844, this paper intends to show the Hegelian motives which inform Young Marx's conception of labor. In order to do so, in the first place, Hegel's account of labor in The Phenomenology of Spirit is reconstructed. In the second place, a counter reading of Marx's manuscript about "alienated labour" was made, in order to make explicit his positive account of labor and to show Hegel's influence on it.

Keywords: Young Marx, labor, alienation, Hegel, Marxism.

Resumo

Com o objetivo de superar as leituras literais e irreflexivas dos Manuscritos econômico-filosóficos de 1844, o seguinte escrito propõe-se identificar os motivos hegelianos, que informam a concepção do trabalho utilizado pelo jovem Marx. Para elo, em primeiro lugar (1), reconstruiu-se a abordagem do problema do trabalho que Hegel leva a cabo na Fenomenologia do espírito. E, em segundo término (2), realiza-se uma leitura em contraposição do manuscrito sobre "o trabalho alienado", dirigida a revelar a concepção positiva do trabalho de Marx, e a mostrar os objetivos hegelianos que a influem.

\section{Palavras-chave: Jovem Marx, trabalho, alienação, Hegel, Marxismo.}

Artículo recibido el 01 de abril de 2015 y aprobado el 26 de junio de 2015

1 Universidad de Buenos Aires, Buenos Aires, Argentina. Correo Electrónico: alexis.gros@uni-konstanz.de 


\section{Introducción²}

En la mayoría de los manuales introductorios al pensamiento de Marx, suele reproducirse maquinalmente la distinción entre las cuatro formas de manifestación del trabajo alienado (entfremdete / entäußerte Arbeit) expuesta en los Manuscritos económico-filosóficos de 1844 (cfr. por ejemplo, Fetscher, 2004). En la sociedad capitalista, se señala una y otra vez, el trabajador se aliena (I) respecto del producto de su trabajo, (II) respecto de su propia actividad laboral, (III) respecto de la esencia genérica (Gattungswesen) humana y (IV) respecto del prójimo.

La repetición irreflexiva de esta conocida fórmula conduce a olvidar que la concepción marxiana del trabajo alienado presupone - y se sustenta en- lo que podría denominarse una noción positiva del trabajo; esto es, una idea más o menos clara acerca de la esencia del trabajo y del rol fundamental que el mismo debería desempeñar en la vida humana. En efecto, al menos tal como lo utiliza el joven Marx en los Manuscritos, el concepto de alienación (Entfremdung / Entäußerung) refiere a la "pérdida de la naturaleza de algo, de su esencia, de tal modo que su existencia actual está divorciada de su naturaleza real" (Skempton, 2010, p. 56).

En este sentido, cuando Marx señala que el trabajo humano está alienado o extrañado, lo que está afirmando es que su verdadero modo de ser ha sido corrompido por las condiciones socioeconómicas del capitalismo. Para decirlo de otra forma: no puede hablarse de la alienación de algo o alguien en la manera en que lo hace el joven Marx si no se cuenta, a priori, con una concepción precisa acerca del deber-ser de ese algo o alguien. El pensador sueco Joachim Israel (1977, p. 96) expresa esta idea de forma precisa:

¿Por qué el hombre habría de sentirse alienado cuando ya no experimenta su trabajo cotidiano como actividad creativa? ¿Por qué habría de sentirse alienado cuando no puede apropiarse de los

2 Agradezco al profesor Rubén Dri por la lectura de este escrito y por sus valiosos comentarios y sugerencias. productos de su trabajo? [...] La respuesta estriba en la necesidad de establecer suposiciones acerca del tipo "normal" o "ideal" del trabajo, sobre la relación "natural" del hombre y sus productos de trabajo y sobre la esencia de la especie humana, para suponer un sentimiento de alienación que el hombre experimentaría en condiciones sociales dadas.

Ahora bien, a pesar de actuar como condición de posibilidad de la crítica marxiana de la alienación, esta concepción positiva del trabajo no es formulada explícitamente por Marx ni en los Manuscritos ni en textos posteriores:

El trabajo es la actividad fundamental y central en la vida humana $y$, potencialmente al menos, una actividad realizadora y liberadora. Aunque esta visión está implícita a lo largo de la obra de Marx, no hay una explicación o defensa explícita de la misma. El tratamiento más completo se encuentra en la concepción del trabajo alienado en los Manuscritos económico-filosóficos; pero incluso allí Marx no expone sus supuestos filosóficos en profundidad. (Sayers, 2011, p. 14)

Por este motivo, si se pretende explicitar y exponer la noción positiva del trabajo del joven Marx, es preciso realizar una lectura "a contrapelo [gegen den Strich]" (cfr. Benjamin, 1965, p. 83) del manuscrito sobre "el trabajo alienado [Die entfremdete Arbeit]". Esto es, una lectura que en lugar de reconstruir por enésima vez las dimensiones de la alienación, intente poner de manifiesto la concepción de la esencia del trabajo que subyace tras ellas ${ }^{3}$.

En términos generales, y de modo provisorio, puede afirmarse que, para el joven Marx (1968), el trabajo verdadero, no-alienado, constituye la actividad vital (Lebenstätigkeit) humana, es decir, la actividad en y mediante la cual el hombre se realiza como tal. En efecto, de acuerdo con Marx, el trabajo es -0 , mejor dicho, debería ser- una actividad libre, voluntaria y creativa en la cual el ser humano transforma su entorno natural y social al tiempo que

3 En "La crítica de la alienación ante el ocaso de la metafísica" realicé un primer intento en este sentido (Gros, 2013). 
se da forma a sí mismo y toma plena conciencia de sus poderes y cualidades.

Los principales intérpretes de la obra marxiana coinciden en que la principal fuente de esta concepción positiva del trabajo es la filosofía de Georg Wilhelm Friedrich Hegel (Popitz, 1967; Sayers, 2011; Fetscher, 2004; Astrada, 2003; D’Hondt, 1972, entre otros). En efecto, si bien a grandes rasgos el itinerario intelectual del joven Marx de 1841 a 1844 puede leerse como un pasaje del idealismo al materialismo $-\mathrm{y}$, en este sentido, como un alejamiento progresivo del pensamiento de Hegel (Engels, 2004; Blumenberg, 1985; Attali, 2007; Balibar, 2006; Cornu, 1950)—, la presencia de leit-motifs hegelianos en la concepción marxiana del trabajo es incontestable.

En un pasaje de los Manuscritos, Marx reconoce explícitamente su deuda con las reflexiones hegelianas sobre el trabajo, no sin señalar, unas líneas más abajo, que el filósofo de Jena no logra atisbar el cariz negativo que la actividad laboral adquiere en la sociedad capitalista, esto es, su carácter alienado o extrañado.

Lo grandioso en la Fenomenología hegeliana y en su resultado final - la dialéctica de la negatividad como el principio creador y movilizador-es, en primer lugar, que Hegel comprende la autogeneración [Selbsterzeugung] del hombre como proceso, la objetivación [Vergegenständlichung] como desobjetivación [Entgegenständlichung], como enajenación [Entäußerung]; que comprende la esencia del trabajo [Arbeit] y que entiende al hombre objetivo, verdadero porque real, como resultado de su propio trabajo. El trabajo es el devenirpara-sí [Fürsichwerden] del hombre dentro de la enajenación o como hombre enajenado. El comportamiento real, activo, del hombre para consigo mismo como ser genérico [Gattungswesen] o su manifestación como un verdadero ser genérico, esto es, como ser humano, sólo es posible si saca hacia afuera [herausschafft] realmente todas sus fuerzas genéricas [Gattungskräfte] -lo que a su vez sólo es posible mediante la cooperación de los hombres, como resultado de la historia-, si se comporta para con ellas como objetos, lo cual en principio, a su vez, sólo es posible en la forma de la alienación.

$[\ldots]$

Hegel se sitúa en el mismo punto de vista que la economía política moderna. Comprende el trabajo como la esencia, como la esencia probatoria del hombre; sólo ve el lado positivo del trabajo, no el negativo. (Marx, 1968, p. 574)

En este conocido pasaje se apoyan la mayoría de los comentaristas para afirmar que la concepción positiva del trabajo del joven Marx tiene como principal fuente de inspiración el tratamiento del trabajo formativo que Hegel realiza en la parte B - autoconciencia (Selbstbewußtsein) - de la Fenomenología del espíritu (Fetscher, 2004; Astrada, 2003; Attali, 2007, entre otros). En los Manuscritos, el propio Marx ayuda a confirmar esta hipótesis, recalcando enfáticamente la importancia de esta obra hegeliana publicada en 1807. Si se quiere estudiar el sistema hegeliano, señala Marx (1968, p. 569), "debe comenzarse con la Fenomenología hegeliana, el verdadero lugar de nacimiento y el secreto de la filosofía hegeliana" (die wahre Gebürtsstätte und das Geheimnis der Hegelschen Philosophie).

El presente escrito se propone poner de manifiesto los leit-motifs hegelianos que informan la concepción positiva del trabajo del joven Marx. Con este objetivo, en el primer apartado (1), se da cuenta del modo en que Hegel aborda el problema del trabajo en la Fenomenología del espíritu. Y en la segunda sección (2), se realiza una lectura a contrapelo del manuscrito sobre "el trabajo alienado" orientada a explicitar la concepción positiva del trabajo de Marx y a mostrar la influencia de Hegel sobre la misma.

\section{El trabajo en la Fenomenología del espíritu de Hegel}

\section{Lineamientos generales de la Fenomenología del espíritu}

En la Fenomenología del espíritu, el problema del trabajo (Arbeit) es abordado de lleno en el capítulo Iv, "La verdad de la certeza de sí mismo" (Die 
Wahrheit der Gewißheit seiner selbst), más específicamente en su parte A, titulada "Sujeción e independencia de la autoconciencia; señorío y servidumbre" (Selbständigkeit und Unselbständigkeit des Selbstwußtseins; Herrschaft und Knechtschaft).

El tratamiento del trabajo humano que Hegel realiza allí no puede ser comprendido cabalmente si se lo aísla del complejo andamiaje argumental de esta chef-d'œuvre. Por esta razón, a continuación se llevará a cabo una reconstrucción sucinta de los lineamientos generales de la Fenomenología, sustentada en las interpretaciones de Rubén Dri $(2006)^{4} y$ Alexander Kojève (2006).

En la Introducción (Einleitung), Hegel caracteriza la Fenomenología del espíritu como la "ciencia de la experiencia de la conciencia" (Wissenschaft der Erfahrung des Bewußtseins) (Hegel, 1991, p. 60; 1989, p. 80). De acuerdo con Dri, para comprender el quid de la empresa teórica que Hegel se propone, es preciso escindir analíticamente esta sentencia en sus partes componentes. La ciencia (Wissenschaft) no es para Hegel una de las disciplinas positivas que se desarrollan en la modernidad - física, química, biología, etc.—, sino la filosofía (Philosophie), esto es, la forma más elevada del conocimiento, la episteme, capacitada para asir lo verdadero: la totalidad (2006, p. 17).

Siguiendo a Dri, en la Fenomenología, el objeto de estudio de la ciencia es la experiencia de la conciencia (Erfahrung des Bewußtseins). A diferencia de Kant, que identifica la experiencia con el conocimiento científico-natural, en Hegel, la experiencia (Erfahrung) es "el camino de la conciencia natural que pugna por llegar al verdadero saber" (der Weg des natürlichen Bewußtseins, das zum wahren Wissen dringt) (Hegel, 1991, p. 54; 1989, p. 72). En otros términos: se trata de todo el recorrido que debe atravesar necesariamente el espíritu humano para advenir desde su forma más pobre, la conciencia natural o de sentido común, hasta su encarnación más elevada, la ciencia o el saber absoluto (absolutes Wissen).

4 Sin dudas, la interpretación de Dri (2006) de la Fenomenología hegeliana hubiera sido inviable sin el magistral trabajo del francés Jean Hyppolite (1974).
Lejos de mantenerse igual a sí mismo a lo largo de este camino, el espíritu se desenvuelve de modo dialéctico, adquiriendo diferentes configuraciones (Gestaltungen) que deben comprenderse como momentos necesarios de su ascenso hacia la ciencia. Es así como, comenzando como certeza sensible (sinnliche Gewissheit), la conciencia se transforma sucesivamente en percepción (Wahrnehmung), entendimiento (Verstand), autoconciencia (Selbstbewußtsein), conciencia desgraciada (unglückliches Bewußtsein), estoicismo (Stoizismus), etc. (Dri, 2006, p. 17). En palabras de Hegel: la experiencia es "el camino del alma [Seele] que recorre la serie de sus configuraciones como estaciones que su naturaleza le pone adelante, depurándose así hasta elevarse al espíritu" (Hegel, 1991, p. 54; 1989, p. 72. Traducción modificada).

Trazando una clara analogía con la novela de formación (Bildungsroman), género literario muy popular en la Alemania de comienzos del siglo XIX, Hegel entiende este recorrido de la conciencia como un proceso de formación (Bildung). "La serie de las configuraciones que la conciencia va recorriendo por este camino constituye más bien la historia detallada de la formación de la conciencia misma hacia la ciencia" (Hegel, 1991, p. 54; 1989, p. 73. Traducción modificada). En efecto, como señala Dri (2006, p. 17), aun cuando estén dirigidas hacia el mundo exterior, las experiencias tanto cognoscitivas como prácticas que realiza la conciencia deben entenderse como un proceso de progresivo autoconocimiento.

Este recorrido, entonces, puede ser visto como un camino en el cual el espíritu va tomando gradualmente conciencia de sí. En este sentido, su estación final, la ciencia, "no es otra cosa que la plenitud de la autoconciencia, en la medida en que la ciencia es el autoconocimiento del espíritu, donde sujeto y objeto coinciden" (Dri, 2006, p. 47). Para Hegel (1991, p. $54 ; 1989$, p. 72), lejos de ser indoloro y aséptico, este proceso de aprendizaje solo es posible gracias al trabajo de lo negativo (die Arbeit des Negativen). En su recorrido hacia la ciencia, el espíritu debe enfrentarse a la angustia, el desengaño y las dudas. Aquello que en un primer momento aparecía como lo ver- 
dadero se muestra luego como falso y superfluo, y esto, naturalmente, tiene consecuencias traumáticas.

La conciencia natural se mostrará solamente como siendo concepto del saber o saber no real. Pero en tanto se considera inmediatamente como el saber real, este camino tiene para ella significado negativo y lo que es la realización del concepto vale para ella más bien como la pérdida de sí misma, ya que por este camino pierde su verdad. Puede ser visto entonces como el camino de la $d u d a$ [Zweifel] o, más propiamente, como el camino de la desesperación [Verzweiflung]. (Hegel, 1991, p. 54; 1989, p. 72. Traducción modificada).

De acuerdo con Hegel (1991, p. 54; 1989, p. 72), para dar cuenta de la experiencia de la conciencia, la ciencia debe operar como fenomenología (Phänomenologie); es decir, debe ocuparse de "la presentación del saber que aparece" (Darstellung des erscheinenden Wissens). Para decirlo de otro modo: en la Fenomenología, Hegel acompaña al espíritu en su recorrido desde la certeza sensible hasta la ciencia, esto es, expone lo que la conciencia experimenta en este camino; pero no desde un punto de vista externo, sino tal como ella lo vivencia. En este sentido, como bien señala Kojève, Hegel utiliza el concepto de fenomenología de una manera similar a como lo hace Edmund Husserl (2009). "La Fenomenología es una descripción fenomenológica (en el sentido husserliano del término)" (Kojève, 2006, p. 39).

Efectivamente, de modo análogo a Husserl, Hegel busca describir aquello que se le manifiesta a la conciencia, pero solo dentro de los límites en que se da para ella (Husserl, 2009, párr. 24). Sin embargo, a diferencia de lo que sucede en la obra de Husserl, la Fenomenología del espíritu opera en dos planos. En ella, desempeña un rol primordial la figura del filósofo - Hegel-, que acompaña a la conciencia en su experiencia. Situado en una etapa más avanzada del recorrido, el filósofo puede adelantarse a la conciencia y revelar tramos del camino a los que ella todavía no ha llegado (Dri, 2001, p. 7) $)^{5}$.

5 No es este el lugar indicado para dar cuenta de las múltiples diferencias que existen entre Hegel y Husserl. Como se verá a
Luego de este bosquejo de los contornos de la empresa teórica que Hegel se propone en la Fenomenología, es preciso decir unas palabras acerca de la compleja estructura de la obra. Siguiendo a Dri (2006, p. 21), la mejor manera de interpretar la Fenomenología consiste en escindirla en tres macrodialécticas, a saber: (1) Dialéctica del espíritu subjetivo, que abarca los capítulos del I al v, (2) dialéctica del espíritu objetivo, capítulo VI, y (3) dialéctica del espíritu absoluto, capítulos viI y viII. Antes de abordar de lleno la primera macrodialéctica, lugar en donde Hegel se ocupa del trabajo humano, resultará útil esbozar muy sucintamente los lineamientos generales de estos tres momentos de la obra.

1. La dialéctica del espíritu subjetivo puede entenderse, en términos generales, como la descripción de la ontogénesis del espíritu, es decir, del desenvolvimiento del alma individual desde la conciencia natural a la ciencia. Para Dri (2006, p. 21), esta macrodialéctica es pasible de ser comprendida como el "encuadre epistemológico" de toda la Fenomenología, y constituye, en este sentido, el núcleo duro de la obra. Esta dialéctica tiene tres momentos, a saber: (a) conciencia (Bewußtsein), (b) autoconciencia (Selbstbewußtsein) y (c) razón (Vernunft).

2. La dialéctica del espíritu objetivo, por su parte, debe comprenderse como la exposición de la filogénesis del espíritu, es decir, del desarrollo histórico de la humanidad en su conjunto. Esta macrodialéctica cuenta también con tres momentos: (a) el espíritu verdadero (Der wahre Geist), encarnado para Hegel en la polis griega; (b) el espíritu autoalienado (Der sich entfremdete Geist), que se corresponde con la revolución francesa, y (c) el espíritu autocerciorado (Der seiner selbst gewisse Geist), que se realiza en la empresa napoléonica y el idealismo alemán (Dri, 2006, p. 21).

3. En cuanto a la dialéctica del espíritu absoluto, se trata de la descripción del desen-

continuación, Hegel supera la concepción meramente objetual, intencional, de la conciencia que sostiene Husserl (Dri, 2006). 
volvimiento de las realizaciones superiores del espíritu: la religión (Religion) y el saber absoluto (absoluter Geist). La dialéctica de la religión tiene los siguientes tres momentos: (a) religión natural (natürliche Religion), con la que Hegel se refiere a las religiones del cercano Oriente; (b) religión del arte (Kunstreligion), que se corresponde con el arte clásico griego; y (c) religión revelada (offenbare Religion): el cristianismo. Por su parte, el saber absoluto constituye la ciencia, esto es, la captación de la totalidad. Hegel considera que este conocimiento supremo se realiza en su propio sistema filosófico.

\section{El lugar del trabajo humano en el camino hacia la autoconciencia}

Kojève concibe la Fenomenología del espíritu como la exposición de la génesis del saber absoluto. En otras palabras, para el autor francés, el propósito de esta obra consiste en describir de qué manera se originan, en la propia experiencia de la conciencia, las premisas o las condiciones suficientes y necesarias para el advenimiento de la ciencia filosófica. En la Fenomenología, señala Kojève, se "muestra cómo y por qué el hombre ha podido llegar al saber absoluto" (2006, p. 182).

Dado que el saber absoluto implica la más completa toma de conciencia de sí por parte del espíritu, esto es, la autoaprehensión y el autoconocimiento absolutos, la pregunta acerca de las premisas del advenimiento de la filosofía está íntimamente ligada al interrogante acerca del origen de la autoconciencia humana. De acuerdo con Kojève (2006, p. 186), en efecto, "para que haya verdaderamente existencia humana, que puede devenir una existencia filosófica, hace falta que haya [...] Autoconciencia". La filosofía verdadera o la ciencia es entonces para Hegel "no como la filosofía kantiana y prekantiana, una filosofía de la Conciencia, sino una filosofía de la Autoconciencia, una filosofía autoconsciente que da cuenta de sí misma, que se justifica a sí misma, que sabe que es absoluta y se revela como tal a sí misma" (p. 189). La primera macrodialéctica de la
Fenomenología está destinada, justamente, a responder la pregunta acerca de cómo surge la autoconciencia humana. "Hay que preguntarse cuándo, por qué y cómo el hombre es llevado a decir 'Yo"' (p. 187).

Para Hegel, en el primer momento de la dialéctica del espíritu subjetivo, esto es, en la conciencia, el hombre jamás puede alcanzar la autoconciencia. En este estadio de su desenvolvimiento, el espíritu se dirige de forma puramente cognitiva a un objeto externo. Al contemplarlo con atención, es absorbido por él, olvidándose por completo de su ipseidad. Dado que toda su atención está enfocada en la cosa, no puede verse a sí mismo como aquél-que-contempla-la-cosa, y, en este sentido se ve inhabilitado a decir "yo" (Kojève, 2006, p. 186).

La exploración meramente contemplativa, pasiva, del mundo, propia de la conciencia, no es suficiente entonces para que el sujeto adquiera conocimiento de sí mismo. En la perspectiva de Hegel, el tránsito de la conciencia a la autoconciencia implica un pasaje de la pasividad a la actividad, de la mera teoría a la praxis. Este pasaje se realiza a través del deseo o la apetencia (Begierde). Cuando el sujeto tiene un deseo - por ejemplo, cuando tiene hambre- es "recordado de sí"; se advierte a sí mismo como un yo carente, diferente al objeto deseado, el cual, a su vez, aparece como un Gegen-stand, como un no-yo. Para Hegel, entonces, si el hombre es por esencia autoconsciente, "es necesario que el Yo humano sea un Yo del Deseo, es decir, un Yo activo, un Yo negador" (Kojève, 2006, p. 188).

Ahora bien, el deseo animal es condición necesaria pero no suficiente para el advenimiento de la autoconciencia humana. Los animales, guiados solo por la apetencia, no son autoconscientes en el sentido enfático del término, sino que cuentan meramente con un sentimiento de sí (Selbstgefühl) (Kojève, 2006, p. 188). En efecto, para Hegel, el hombre solo deviene autoconsciente si puede contemplarse a sí mismo en un objeto exterior estable. "[S]u verdad [Wahrheit] sólo estaría en que su propio ser para sí se presentase ante ella [la conciencia] como objeto independiente [selbständiger Gegenstand] o, lo que es lo mismo, en que el objeto se presentase 
como esta pura certeza de sí mismo" (1991, p. 115; 1989 , p. 148$)^{6}$.

Esto no es posible para el animal, ya que la Begierde lo impulsa al consumo inmediato del objeto natural y, en consecuencia, a la aniquilación del mismo. La cosa es devorada (gefressen) e incorporada, y desaparece así como objeto independiente. De acuerdo con Hegel (1991, p. 112; 1989, p. 143), el sujeto de la Begierde nunca logra satisfacerse completamente porque, poco después de haber devorado la cosa, retorna al estado de carencia en el que se encontraba antes de consumirla, y se ve obligado a emprender la búsqueda de un nuevo objeto. Al saciar su apetencia, entonces, el animal no hace más que reproducirla ad infinitum.

Para Hegel (1991, p. 112; 1989, p. 145), “[1] a autoconciencia sólo alcanza su satisfacción en otra autoconciencia" (Das Selbstbewußtsein erreicht seine Befriedigung nur in einem anderen Selbstbewußtsein). En efecto, "[1]a autoconciencia es en y para sí en cuanto que y porque es en sí y para sí para otra autoconciencia; es decir, sólo es en cuanto se la reconoce" (Hegel, 1991, p. 113; 1989, p. 145). Desde la perspectiva hegeliana, el hombre puede alcanzar la autoconciencia gracias a que es movilizado por un deseo específicamente humano, un deseo divergente en cuanto a su estructura y objeto a la Begierde animal: el deseo de reconocimiento (Anerkennung) (Kojève, 2006, p. 190). El sujeto humano desea el deseo del alter ego, es decir, quiere ser reconocido por otro hombre - $y$, en última instancia, por todos los hombres - como una persona valiosa y digna (Honneth, 1992). "El deseo no es humano -o más exactamente 'humanizante,' 'antropógeno'- sino a condición de ser orientado sobre otro Deseo y sobre otro Deseo" (Kojève, 2006, p. 190). $\mathrm{Al}$ ser reconocido por otro, el sujeto humano puede "salir de sí" y contemplarse a sí mismo reflejado en el alter ego; puede verse desde los ojos del prójimo

6 Kojève apuntala esta idea hegeliana cuando señala: "Para que haya Autoconciencia, para que haya filosofía, es preciso que haya trascendencia de sí con relación a sí en tanto que dado" (Kojève, 2006, p. 190), es decir, el hombre debe salir de sí para poder contemplarse; debe tomar distancia de sí mismo. y, de esa manera, corroborar (bewähren) y reforzar la propia identidad y autoestima (Honneth, 1992).

Ahora bien, de acuerdo con Hegel (1991, p. 116; 1989, p. 149), el reconocimiento intersubjetivo no está garantizado desde el vamos. Dado que todos los seres humanos apuntan a ser reconocidos como superiores por sus prójimos, se establece una "lucha a vida o muerte" (Kampf auf Leben und Tod) por el reconocimiento, una lucha de puro prestigio, en la cual cada uno quiere someter el deseo del otro (Kojève, 2006, p. 191).

Esta lucha es a vida o muerte porque el hombre que quiere ser reconocido como tal debe estar dispuesto a poner en juego tanto su propia vida biológica como la ajena, es decir, a matar o morir (Kojève, 2006, p. 191). En otras palabras: para ser reconocido, el sujeto debe probar su humanidad ante el otro, y para ello tiene que dar muestras de que es algo más que un mero animal; debe hacer ostensible que supera el instinto de autoconservación, identificado por Hegel (1991, p. 116; 1989, p. 149) con la inmediatez de la vida (Leben) biológica, en pos de la consecución de un fin espiritual: el reconocimiento.

Ahora bien, para Hegel (1991, p. 113), ambos contrincantes no van hasta el final en esta lucha a muerte. Si así fuera, se plantearían dos escenarios catastróficos para la humanidad: o bien la muerte de los dos combatientes, o bien la muerte de uno de ellos. En los dos casos, el advenimiento de la autoconciencia humana se vería bloqueado $-y$ por tanto también el desarrollo de la filosofía-, ya que, como se señaló más arriba, se necesitan al menos dos hombres para que exista una realidad propiamente humana, autoconsciente (Kojève, 2006, p. 194). "Es preciso, por lo menos, ser dos para ser humano" (Kojève, 2006, p. 194). Por esta razón, debe suponerse que solo uno de los contrincantes estará dispuesto a arriesgar su vida por el reconocimiento, mientras que el otro sucumbirá al miedo a la muerte, mantendrá su vida biológica pero al precio de perder su humanidad.

Es de esta manera como se origina la relación entre señor (Herr) y siervo (Knecht). El segundo se somete a los designios del primero, y lo reconoce 
como superior, pero sin ser a su vez reconocido por él. "[U]na es la conciencia independiente [selbständige] que tiene por esencia el ser para sí, la otra la conciencia dependiente [unselbständige], cuya esencia es la vida o el ser para otro; éste es el señor [Herr], aquél, el siervo [Knecht]" (Hegel, 1991, p. 117; 1989, p. 150. Traducción modificada).

Aquí es donde aparece el problema del trabajo (Arbeit) en la Fenomenología. En efecto, la superioridad "espiritual" del señor sobre el siervo se materializa en el hecho de que el segundo debe trabajar al "servicio" (Dienst) del primero. Hegel describe este estado de cosas, en primer lugar, desde la perspectiva del señor (I) y, luego, desde la perspectiva del siervo (II).

(I) Gracias a la mediación del trabajo del siervo, que transforma la naturaleza circundante para volverla acorde a los designios del señor, este puede consumir la cosa de modo inmediato. En otras palabras: el amo se ve eximido de las pesadas cargas que implica la elaboración de la materia prima para su consumo - por ejemplo la cocción de un alimento-, y se entrega al puro goce (Genuß) hedonista de los productos del trabajo servil - la ingesta y degustación del mismo- (Kojève, 2006, p. 198). Ahora bien, por paradójico que suene, Hegel (1991, p. 119; 1989, p. 151) considera que, de esta forma, el amo - que parecía haber superado su vida biológica al triunfar en la lucha por el reconocimiento- no hace más que retornar a la animalidad de la Begierde. Y esta, como se señaló, jamás puede brindar autoconciencia, sino meramente un sentimiento de sí (Selbstgefühl).

A esta recaída en la animalidad se le suma otro obstáculo que termina por convertir el señorío en un "callejón sin salida existencial" (Kojève, 2006, p. 198). Como se señaló, el señor puso en juego su existencia animal con el objetivo de ser reconocido por otra autoconciencia, por otro hombre. Sin embargo, al fin de cuentas, este riesgo termina siendo en vano. El amo no puede encontrar la "satisfacción" (Befriedigung) en el reconocimiento del esclavo porque este no es para él una autoconciencia, un hombre, sino una "conciencia dependiente" (unse- lbständige Bewußtsein) (Hegel, 1991, p. 119; 1989. p. 152). Para decirlo de otro modo: el amo jamás puede alcanzar la plena autoconciencia porque la relación señor-siervo bloquea lo que Heinrich (2009; Gros, 2013b) denomina doble reconocimiento (doppelte Anerkennung) o reconocimiento recíproco: el siervo reconoce al señor, pero este no reconoce a aquel (Hegel, 1991, p. 119; 1989, p. 152).

Es a partir de estas premisas que, en lo que puede entenderse como un gesto que prefigura la confianza mesiánica de Marx en la clase obrera, Hegel deduce que "[1] a verdad de la conciencia independiente es [...] la conciencia servil” (Die Wahrheit des selbständigen Bewußtsein ist [...] das knechtische Bewußtsein) (Hegel, 1991, p. 119; 1989, p. 153). Contra todas las apariencias, entonces, la verdadera autoconciencia solo puede ser adquirida no por el señor sino por el siervo. Como se mostrará a continuación, el trabajo desempeñará un rol clave en la humanización del esclavo.

(II) Para Hegel, la experiencia que realiza el siervo tiene tres momentos fundamentales: el temor a la muerte (Furcht des Todes) o angustia, el servicio (Dienst) y el trabajo (Arbeit) (Dri, 2001; 2006, pp. 180-185). Como se mostrará a continuación, contra todos los pronósticos, esta triple experiencia le otorga al esclavo una ventaja comparativa por sobre el amo a la hora de adquirir conciencia de sí.

Tal como se mostró más arriba, el siervo fue derrotado por el amo en la lucha por el reconocimiento debido a que no se atrevió a arriesgar su vida biológica por un fin espiritual. Desde la perspectiva de Hegel, en efecto, el esclavo deviene tal porque es paralizado por la angustia, un temor fundamental, esencial a la conditio humana, que no se dirige a un objeto particular - como por ejemplo el miedo a una serpiente-, sino al carácter finito de la existencia o, lo que es lo mismo, a la muerte (Dri, 2006, p. 181$)^{7}$.

En este sentido, puede afirmarse que el esclavo se subordina al amo porque, en primera instancia, no

7 Como bien señala Dri (2006, p. 181), el problema de la angustia ha sido abordado en profundidad por la filosofía existencial, especialmente por Kierkegaard y Heidegger (2006). 
logra superar el sometimiento a su propia naturaleza, a su instinto de autoconservación. Prima facie, entonces, pareciera que la experiencia de la angustia solo tiene consecuencias negativas para el siervo: lo paraliza y lo torna un ser dependiente tanto de la naturaleza como del señor. Sin embargo, como suele suceder en la Fenomenología, aquello que a primera vista parece lo verdadero se troca, luego de una inspección más cuidadosa, en su contrario. Para Hegel, en efecto, la experiencia de la angustia tiene consecuencias beneficiosas para el desarrollo de la autoconciencia en el esclavo. El miedo a la muerte "disuelve interiormente" la conciencia; conduce a "la fluidificación [Flüssigwerden] absoluta de toda subsistencia" (Hegel, 1991, p. 119; 1989, p. 153). Con la angustia, "todo lo sustancial, lo objetual, o sea, todo lo permanente, se pone en movimiento vertiginoso" (Dri, 2006, p. 181), y así se vuelve patente el carácter puramente negativo de la autoconciencia. Gracias a esta experiencia límite, el esclavo puede captar el vado ávido, la nada, que constituye su esencia en cuanto autoconciencia (Hegel, 1991, p. 119; 1989, p. 153).

En el servicio, esto es, en su sometimiento al señor, el esclavo pasa de la actitud contemplativa a la práctica. La negatividad absoluta que experimentó en la angustia se traslada a la naturaleza por medio del trabajo servil (Dri, 2006, p. 181). El siervo puede así ver reflejada su esencia humana en el producto de su trabajo y devenir de este modo para sí. En palabras de Hegel:

[S]in la disciplina del servicio y la obediencia, el temor se mantiene en lo formal y no se propaga a la realidad consciente de la existencia. Sin el formar [das Bilden], el temor permanece interior y mudo, y la conciencia no deviene para ella misma. (Hegel, 1991, p. 121; 1989, p. 157)

Se llega así al núcleo de la concepción hegeliana del trabajo humano. De modo simplificado y esquemático, esta concepción puede ser resumida en dos tesis principales que se encuentran íntimamente entrelazadas $^{8}$. (a) Mediante el trabajo, el hombre

8 Esta escisión de la concepción hegeliana del trabajo en dos tesis es una simplificación que ha sido realizada con fines meramente heurísticos. logra dominar consciente y voluntariamente $-\mathrm{y}$, por tanto, liberarse de las cadenas de - la naturaleza. Este dominio sobre la naturaleza tanto "externa" - su mundo circundante- como "interna" - los propios instintos 9 - tiene lugar como proceso de formación (Bildung). (b) El trabajo hace posible el desarrollo de la autoconciencia en cuanto que crea un mundo cultural en el que el hombre puede verse reflejado y reconocerse como tal. Veamos estas dos tesis más de cerca.

(a) Como se señaló más arriba, en la lucha por el reconocimiento, el siervo fue derrotado debido a que no pudo superar su instinto de autoconservación; es decir, fue sometido por el señor porque primero se sometió a su propia naturaleza, a sus instintos inmediatos. Pero ahora, al trabajar en servicio del amo, el siervo debe reprimir estos instintos, que lo impulsan a consumir la cosa natural de forma inmediata, y dedicar sus esfuerzos a transformar la naturaleza de acuerdo con los designios de su señor. En otras palabras: el siervo debe ahora dominar tanto la naturaleza "interna" como "externa” y modificarlas en función de una idea - lo que quiere el señor-.

El trabajo, señala Hegel, es "apetencia reprimida, desaparecer contenido o él forma [gehemmte Begierde, aufgehaltenes Verschwinden, oder sie bildet]" (Hegel, 1991, p. 120; 1989, p. 154. Traducción modificada). El siervo contiene, reprime, su apetencia en pos de un concepto - el deseo del amo-, da forma así a su naturaleza "interna" - esto es, disciplinando sus instintos inmediatos- y a la naturaleza "externa" - transformando el mármol en mesa y el árbol en silla (Dri, 2006, p. 183)—. Desde una perspectiva dialéctica, claro está, estos dos momentos, la naturaleza "externa" e "interna", no son compartimientos estancos; antes bien, "se transforman mutua, continua e ininterrumpidamente en su interior, de tal forma que no es posible diferenciarlos

9 La distinción entre naturaleza "externa" e "interna" es también de carácter heurístico y no debe ser tomada al pie de la letra. Desde una posición dialéctica como la hegeliana, en efecto, no puede escindirse a la naturaleza en dos compartimentos estancos. Esto implicaría reproducir el dualismo sujeto-objeto que Hegel quiere superar. 
radicalmente unos de otros" (Horkheimer, 1968, p. 49).

El hombre no puede ser tal sin su mundo ni viceversa: al transformar el mundo, se transforma a sí mismo, y al transformarse, transforma el mundo. El trabajo servil, entonces, da inicio a un proceso de formación:

En el doble sentido de la palabra: por una parte, forma, transforma el Mundo [...], volviéndolo más adaptado al Hombre; por otra parte transforma, forma, educa al Hombre, lo humaniza haciéndolo más conforme a la idea que se forma de sí mismo y que no es, al principio, son una idea abstracta, un ideal. (Kojève, 2006, p. 204)

(b) Tal como fue expuesto anteriormente, para lograr la autoconciencia, el sujeto precisa contemplarse a sí mismo en un objeto exterior estable. "[S] u verdad sólo estaría en que su propio ser para sí se presentase ante ella [la conciencia] como objeto independiente o, lo que es lo mismo, en que el objeto se presentase como esta pura certeza de sí mismo" (Hegel, 1991, p. 115; 1989, p. 148). En este sentido, el señor no puede tornarse jamás autoconsciente, puesto que, al recaer en la animalidad de la Begierde, destruye e incorpora inmediatamente la cosa preparada por el siervo, y pierde así todo objeto independiente en el cual contemplarse. Por el contrario, el siervo, obligado a renunciar a su apetencia y a trabajar en servicio del amo, le da forma a la naturaleza; expresa su negatividad en ella pero no la consume. "La negatividad pasa a ser, en consecuencia, forma, delimitación permanente. El mármol se transforma en estatua; el campo, en parque; la madera, en silla" (Dri, 2006, p. 183). La cosa, el producto del trabajo, en este sentido, permanece como un objeto independiente en el cual el siervo puede verse reflejado, de esta manera adquiere conciencia de sí. En palabras de Hegel (1991, p. 120), el siervo "se pone en cuanto tal en el elemento de lo permanente y se convierte de este modo en algo para sí mismo, en algo que es para sî. El esclavo, entonces, exterioriza su esencia en el objeto externo, y construye un mundo humano, cultural, en el cual puede reconocerse a sí mismo.
Por supuesto, el camino de la conciencia hacia la ciencia no termina aquí. Al finalizar la dialéctica de la independencia, comienza la de la libertad $^{10}$. Esta sucinta exposición de la Fenomenología, sin embargo, concluye aquí: ya contamos con los lineamientos generales de la concepción hegeliana del trabajo.

\section{Motivos hegelianos en la concepción positiva del trabajo de Marx: una lectura a contrapelo de los Manuscritos económico-filosóficos de 1844}

\section{El núcleo filosófico de los Manuscritos económico-filosóficos de 1844}

Como lo señala su título, los Manuscritos económico-filosóficos cuentan con un núcleo económico y un núcleo filosófico (Dal Pra, 1971). Los motivos de la economía política inglesa y de la filosofía alemana, que junto al socialismo francés son las principales fuentes del pensamiento marxiano, se dan cita por primera vez en este texto de 1844. Por supuesto, el interés de la presente indagación se centra fundamentalmente en el núcleo filosófico de los Manuscritos, caracterizado por el entrecruzamiento de las influencias de Hegel y del hegeliano de izquierda Ludwig Feuerbach.

En los Manuscritos, Marx retoma la crítica materialista de la religión y de la filosofía especulativa emprendida por Feuerbach en La esencia del cristianismo (Feuerbach, 1969) y las Tesis provisionales para la reforma de la filosofía (Feuerbach, 1950), respectivamente, a los fines de enfrentarse con Hegel y los "teólogos críticos", término que utiliza para referirse a los denominados hegelianos de derecha (Marx, 1968). El punto de partida de Marx es el mismo que el de la filosofía de Feuerbach: no el espíritu o la idea, sino el hombre material concreto, que vive en la naturaleza y con el prójimo (Löwith, 2008). El joven Marx se inspira entonces en los dos elementos esenciales del pensamiento feuerbachiano: el naturalismo y el humanismo, expre-

10 Para un análisis minucioso de esta dialéctica, cfr. Dri (2006). 
sado este último en el concepto de esencia genérica (Gattungswesen).

Pero aquí no acaba la influencia de Feuerbach en Marx. El apartado central y más famoso de los Manuscritos, el dedicado al trabajo alienado, retoma la reelaboración feuerbachiana del concepto hegeliano de alienación (Entäußerung / Entfremdung). A diferencia de Hegel, Feuerbach no concibe la alienación como un momento provisorio - aunque necesario- en el recorrido del espíritu hacia el saber absoluto, sino más bien como un acuciante problema existencial de la humanidad bajo la égida del cristianismo. En La esencia del cristianismo, Feuerbach (1969) señala que el ser humano se divorcia de sus cualidades más valiosas al atribuírselas a Dios, un ser que brota de su propia imaginación. Mientras más pone el hombre en la divinidad, menos conserva para sí mismo; más mísero e impotente se vuelve. De modo análogo a como lo había hecho en los artículos de los Deutsch-Französische Jahrbücher respecto de la alienación política (Fetscher, 2004) ${ }^{11}$, en los Manuscritos, Marx transvasa el esquema feuerbachiano de la crítica de la religión al estudio de la alienación económica. En un pasaje de este texto de 1844, el pensador de Tréveris reconoce explícitamente su deuda con Feuerbach:

Feuerbach es el único que tiene una relación seria y crítica con la dialéctica hegeliana y que ha realizado verdaderos descubrimientos en este terreno; es en realidad el verdadero superador de la vieja filosofía. Lo grandioso del logro y la simplicidad sin ruido con la cual Feuerbach se lo comunica al mundo se encuentran en una asombrosa contraposición con la relación inversa. La gran acción de Feuerbach es 1) la demostración de que la filosofía no es otra cosa que la religión puesta en forma de ideas y desarrollada en el pensamiento; por tanto debe ser condenada del mismo modo, otra forma y modalidad de existencia de la alienación [Entfemdung] de la esencia humana. 2) La fundación del verdadero materialismo [wahrer Materialismus] y de la ciencia real [reele Wissenschaft], en tanto Feuerbach convierte a la relación social del "hom-

11 Me refiero a "Sobre la cuestión judía" (Marx, 1981a) y "Para una crítica de la Filosofía del Derecho de Hegel" (Marx, 1981b). bre con el hombre" [das gesellschäftliche Verhältnis des Menschen zum Menschen] en el principio fundamental de la teoría. 3) En tanto le opone a la negación de la negación, que postula ser lo absolutamente positivo, lo positivo positivamente basado en sí mismo y que descansa en sí mismo.

(Marx, 1968, pp. 568-569)

Sin embargo, en los Manuscritos existe también una crítica velada a Feuerbach que, a pesar de no ser tan explícita como la que se encuentra en las “Tesis sobre Feuerbach" (Marx, 2004) y en La ideología alemana (Marx y Engels, 2004), no deja de ser tal. En efecto, Marx apercibe que, a pesar de sus ya señalados logros, la filosofía feuerbachiana carece de ciertos elementos teóricos que sí pueden encontrarse en el pensamiento de Hegel, a saber: la dialéctica y la concepción del trabajo (Dal Pra, 1971). Ahora bien, dado que Marx rechaza de plano los rasgos mistificados e idealistas de la filosofía hegeliana, es claro que no puede retomar elementos de la misma sin antes hacerlos pasar por el tamiz materialista del pensamiento feuerbachiano. Esto resulta en cierta medida paradójico: Marx se inspira en Hegel para criticar a Feuerbach, pero, al mismo tiempo, precisa de Feuerbach para criticar a Hegel ${ }^{12}$.

\section{Las cuatro dimensiones del trabajo alienado}

En el apartado titulado "El trabajo alienado" perteneciente al primer manuscrito, el joven Marx diferencia cuatro formas de manifestación del trabajo alienado. Como se señaló más arriba, en la actualidad esta distinción es reproducida de modo maquinal por la mayoría de los manuales introductorios a la obra marxiana. A los fines de superar esta lectura irreflexiva de la obra del joven Marx, el presente escrito se propone explicitar la concepción positiva del trabajo que actúa como condición de posibilidad de la crítica de la alienación y poner de manifiesto los leit-motifs hegelianos que la informan. Con este objetivo, como también fue oportunamente consignado en la introducción, es necesario realizar una

12 Este no es el lugar indicado para realizar un análisis pormenorizado del vínculo de Marx con Feuerbach. Para un tratamiento más profundo, cfr. Löwith (2008), Dal Pra (1971), Attali (2007), Fetscher (2004) y Engels (2004), entre otros. 
lectura a contrapelo del apartado en cuestión, esto es, una lectura que, en lugar de concentrarse en las cuatro dimensiones de la alienación, se esfuerce por explicitar la noción de la esencia del trabajo humano que subyace oculta tras ellas.

Antes de proceder a realizar esta lectura a contrapelo, será menester repetir, por enésima vez, aunque sea de modo sucinto, las cuatro dimensiones que, para Marx, adquiere el trabajo alienado en la sociedad capitalista. (I) El trabajador se aliena respecto del producto de su trabajo en tanto este se le opone como una fuerza extraña y amenazante. Se convierte en "siervo de su objeto" (Knecht seines Gegenstandes) (Marx, 1968, p. 512). "El objeto que el trabajador produce, su producto, se le enfrenta como un ser extraño [fremdes Wesen], como un poder independiente [unabhängige Macht] del productor" (p. 510). (II) El obrero se aliena respecto de su propia actividad laboral, se autoaliena; es decir, no se siente potente, realizado y satisfecho cuando trabaja, sino, por el contrario, debilitado, desrealizado, infeliz y hasta castrado. "Si el producto del trabajo es la alienación [Entäußerung], entonces la producción misma debe ser la alienación activa [die tätige Entäußerung], la alienación de la actividad [die Entäußerung der Tätigkeit], la actividad de la alienación [die Tätigkeit der Entäußerung]" (p. 513). (III) El trabajador se aliena respecto de su esencia genérica (Gattungswesen) humana que, para Marx, consiste en la producción libre y consciente (freie bewußte Tätigkeit).

Se llega al resultado de que el hombre (el trabajador) sólo se siente actuando libre en sus funciones animales: comer, beber y copular, como máximo en la vivienda, el ornamento, etc., y en sus actividades humanas se siente simplemente como un animal. (Marx, 1968, pp. 513-514)

(IV) El obrero se aliena también respecto del prójimo. Se produce la "alienación del hombre respecto del hombre" (Entfremdung des Menschen von dem Menschen):

Lo que vale para la relación del hombre con su trabajo, con el producto de su trabajo y consigo mismo, vale para la relación del hombre con el otro hombre, así como también para el trabajo y el objeto de trabajo del otro hombre. (Marx, 1968 , p. 517) $)^{13}$

\section{En busca de leit-motifs hegelianos en la concepción positiva del trabajo de Marx}

Llegó el momento de realizar la prometida lectura a contrapelo del manuscrito sobre "el trabajo alienado". Como se señaló, la misma buscará explicitar la concepción positiva del trabajo del joven Marx y poner de manifiesto los leit-motifs hegelianos que la informan. Para llevar a cabo esta tarea, se retomarán los señalamientos marxianos acerca de la enajenación del obrero respecto de la esencia genérica (Gattungswesen) humana como un punto de partida para releer en nueva clave las restantes manifestaciones del trabajo alienado. En esta, la tercera dimensión de la alienación bosquejada por Marx (1968, pp. 513-514), se encuentran en ciernes los elementos teóricos necesarios para reconstruir su concepción positiva del trabajo humano. Como se mostrará en lo que sigue, es posible afirmar que existen claras líneas de continuidad entre dos de las afirmaciones principales de Marx acerca de la Gattungswesen humana $-p$ y $q-$ y las dos tesis hegelianas sobre el trabajo que fueron delineadas más arriba $-a \mathrm{y} b-$.

(p) De acuerdo con Marx, el carácter de una especie (Gattungscharakter) - esto es, su diferenttia specifica- es determinado por el cariz particular de su actividad vital (Lebenstätigkeit). La actividad vital distintiva del animal consiste en dejarse llevar irreflexivamente por sus necesidades físicas o instintos. "El animal es inmediatamente uno con su actividad vital. No se diferencia de ella. Es ella" (Marx, 1968, p. 515). En contraposición, el modo de operar característico del hombre es el "trabajo" (Arbeit), entendido como "actividad libre y consciente" (freie bewußte Tätigkeit) de transformación de la naturaleza. "El hombre convierte su actividad vital misma en objeto de su voluntad y de su conciencia. [...] La actividad

13 Como se desprende de lo antedicho, no es mi intención aquí reproducir una vez más todo lo que afirma Marx sobre cada una de estas dimensiones tal como lo hacen la mayoría de los manuales introductorios a su pensamiento (cfr. Rieznik, 2007; Fetscher, 2004). Basta con señalar los rasgos característicos de cada una de ellas. 
vital consciente diferencia al hombre inmediatamente de la actividad vital animal" (Marx, 1968, p. 515). Para decirlo de otro modo: en contraste con el animal, que es heterónomo e inconsciente, el ser humano reconoce su "actividad productora" (produzierende Tätigkeit) como propia y es capaz de dominarla a voluntad.

Ahora bien, en cierto sentido, es correcto afirmar que el animal también "trabaja”. En efecto, la experiencia nos enseña que los animales transforman su entorno natural para construir nidos, hormigueros, colmenas, guaridas, etc. Sin embargo, de acuerdo con Marx, esta actividad productiva no puede ser concebida como trabajo en el sentido enfático del término - esto es, en un sentido humano-, puesto que no se lleva a cabo libre y voluntariamente, sino "bajo el señorío de la necesidad física inmediata" (unter der Herrschaft des unmittelbaren physischen Bedürfnisses) (Marx, 1968, p. 515). En otros términos: la "producción" animal no es resultado de una decisión autónoma y autoconsciente, sino más bien una mera prolongación del instinto biológico. El ser humano, en contraste, puede producir "libre de la necesidad física y sólo produce verdaderamente en libertad de la misma" (frei vom physischen Bedürfnis und erst wahrhaft produziert in der Freiheit von demselben) (Marx, 1968, p. 515). Desde la perspectiva marxiana, entonces, el trabajo humano solo es tal cuando supera los impulsos biológicos inmediatos, y es tanto más "verdadero" (wahrhaft), tanto más auténtico, cuanto más se autonomiza de ellos; es decir, cuanto más se aleja del reino de la necesidad para adentrarse en el de la libertad. Siguiendo estos lineamientos, la creación de una obra de arte, siempre y cuando se amolde al lema l'art pour l'art, sería más humana que la producción de alimentos u otros bienes destinados a la supervivencia. En palabras de Sayers (2011, p. 22): “[P]ara Marx [...] el arte es la forma más alta de la actividad creativa, actividad creativa libre, la forma más alta de trabajo. Los animales no son capaces de esa actividad, no son libres".

Como puede observarse, esta distinción tajante entre actividad vital animal y humana tiene claras resonancias hegelianas. Al postularla, el joven Marx reproduce, con una terminología diferente y en otro contexto filosófico, la primera tesis hegeliana sobre el trabajo antes bosquejada (a). Tal como se señaló, para Hegel, a través del trabajo, el hombre logra controlar consciente y voluntariamente tanto la naturaleza "interna" como la "externa", dando inicio así a un proceso de Bildung. Hegel considera que lo propio del animal es dejarse llevar por la Begierde, esto es, someterse a los ciegos designios de los impulsos biológicos inmediatos. El trabajo humano, en cambio, es gehemmte Begierde, apetencia reprimida, en pos de la realización de un fin espiritual o ideal. El siervo, el primer trabajador humano en el sentido enfático de la palabra, debe contener y disciplinar los apremios de su apetencia animal, que lo impulsa a consumir inmediatamente la cosa, para transformar el mundo circundante de acuerdo con los designios del amo. De esta manera, supera su sujeción a su propia naturaleza "interna" —es decir, consigue controlar libre y conscientemente los propios instintos-, a la vez que logra domar a la naturaleza "externa".

Ahora bien, afirmar que el ser humano no se deja arrastrar por sus necesidades biológicas inmediatas sino que las domina libre y conscientemente no implica, para Marx, postular una concepción ascética del trabajo como la propia del calvinismo según Max Weber (1988; Gros, 2015). En efecto, en su actividad laboral, el hombre debe "realizarse a sí mismo" (sich verwirklichen); debe "afirmarse" (sich bejahen), "sentirse bien" (wohl fühlen) y "en casa" (zu Hause) (Marx, 1968, p. 513). La energía y la fuerza desplegadas deben ser vividas como propias; el trabajador debe sentirse sujeto de su actividad, debe vivenciar su operar en el mundo como poderío, y no como "impotencia" (Ohnmacht) o "padecimiento" (Leiden) (p. 514).

Ahora bien, a diferencia de Hegel, Marx advierte la dimensión negativa que adquiere el trabajo en la sociedad capitalista, esto es, su carácter alienado o extrañado. Las condiciones de trabajo prevalecientes en el capitalismo, marcadas por la necesidad de vender la fuerza de trabajo al mejor postor y por la división del proceso laboral en actividades mínimas 
que convierten al obrero en mero apéndice de la maquinaria, impiden el libre despliegue de la actividad vital y, en este sentido, alienan al hombre. Marx muestra esto llevando a cabo una suerte de descripción fenomenológica de la situación inhumana en la que se halla el obrero en la sociedad moderna. En el capitalismo, la actividad vital "aparece" (erscheint) no como libre y consciente, sino como "trabajo esclavo" (Zwangsarbeit); el obrero no se afirma cuando la ejerce, sino que "se niega" (sich verneint); no se realiza a sí mismo, sino que "se desrealiza" (sich entwirklicht); no se siente a gusto ni en casa, sino "infeliz" (unglücklich) y "fuera de sí" (außer sich). En una palabra, el trabajo es vivido como un "sacrificio" (Aufopferung), como una "castración" (Entmannung) (Marx, 1968, 513).

Para Marx, en la sociedad burguesa, se produce una inversión irracional de medios y fines. La actividad vital de la especie humana no aparece como fin en sí mismo, sino como mero "medio para la existencia" (Mittel für Existenz); no se satisfacen las necesidades físicas para poder producir, sino que se produce para satisfacer las necesidades físicas. El trabajador solo se siente realizado cuando está fuera del trabajo, esto es, en sus "funciones animales" (tierische Funktionen) - comer, beber, copular, etc. - y vivencia sus "funciones humanas" (menschliche Fuktionen) como una tortura. "Lo animal se convierte en lo humano, y lo humano en lo animal" (Das Tierische wird das Menschliche und das Menschliche das Tierische) (Marx, 1968, p. 514).

(q) También puede encontrarse una clara consonancia entre la concepción positiva del trabajo del joven Marx y la segunda tesis de Hegel sobre el trabajo bosquejada más arriba $(b)$. Según esta tesis hegeliana, el trabajo actúa como condición de posibilidad del desarrollo de la autoconciencia en tanto produce un mundo cultural en el que el hombre puede espejarse y reconocerse como tal. En la misma línea, Marx señala que el hombre "se objetiva" (sich vergegenständlicht) en el producto de su trabajo, esto es, "se duplica" (sich verdoppelt) a sí mismo al proyectar su esencia en una cosa externa (Marx, 1968, p. 516). Esta duplicación permite el advenimiento de la reflexividad; el hombre puede ahora contemplarse a sí mismo, pero no en el éter del pensamiento puro - como sucede en la reflexión teorizada por autores como Husserl (2009, párr. 38) -, sino en el plano de la materialidad; esto es, en el mundo cultural creado por él mismo.

A través de ella [de la producción], la naturaleza aparece como su obra y su realidad [sein Werk und seine Wirklichkeit]. El objeto del trabajo es por tanto la objetivación de la vida genérica del hombre [die Vergegenständlichung des Gattungslebens des Menschen] [...] él no sólo se duplica [sich verdoppelt $]$ en la conciencia, intelectualmente, sino activa [werktätig], verdaderamente [wirklich], y se contempla a sí mismo en un mundo creado por él mismo. (Marx, 1968, 516)

Ahora bien, desde la perspectiva marxiana, no alcanza solo con contemplarse en el producto de trabajo. Esto sería permanecer en el plano de la mera teoría. De los señalamientos de Marx en torno a la primera dimensión de la alienación, puede deducirse que luego de objetivarse en la cosa, el hombre debe superar la distancia que lo separa de la misma apropiándose de ella, esto es, enriqueciéndose física y espiritualmente a través del aprovechamiento de los propios poderes sedimentados en ella. Para comprender esta posición correctamente, es preciso no confundir esta "apropiación" (Aneignung) (Marx, 1968, p. 520) del producto de trabajo, que Marx considera necesaria y fundamental para el ser humano, con la propiedad privada capitalista, esto es, con la acumulación de riquezas por parte del individuo burgués. De lo que se trata para Marx es de un enriquecimiento físico y espiritual de la humanidad en su conjunto, y no del enriquecimiento privado de un sujeto egoísta (Gros, 2013a).

De lo afirmado se desprende que, para el joven Marx, el trabajador y el producto de su trabajo deben permanecer unidos, no pudiendo divorciarse jamás. "En tanto el trabajo alienado le arranca [entrei $\beta t$ ] al hombre el objeto de su producción, le arranca su vida genérica [Gattungsleben], su verdadera objetividad genérica [Gattungsgegenständlichkeit]" (Marx, 1968, p. 520). Por esta razón, el ser humano debe 
ejercer dominio consciente sobre los objetos de su producción, debe apropiarse del entorno cósico generado en la actividad laboral, utilizando en su provecho las potencias depositadas en él. El "mundo cósico" (Sachenwelt) debe ser puesto al servicio de "mundo humano" (Menschenwelt) (Marx, 1968, p. 510); los avances técnicos, la sofisticación y la civilización sedimentadas en los objetos culturales deben redundar en un mejoramiento de la vida del hombre.

Sin embargo, nuevamente, yendo más allá de Hegel, Marx constata que en el capitalismo, los términos del vínculo deseable entre sujeto y objeto se encuentran invertidos. El hombre no controla el producto de su trabajo, sino que cae preso de su dominio, y se convierte en siervo del objeto que él mismo creó. El entorno cultural aparece como un "mundo objetivo extraño" (fremde gegenständliche Welt) y "hostil" (feindlich), como un "poder independiente" (unabhängige Macht) que se opone al trabajador (Marx, 1968, p. 514). El hombre, consecuentemente, no se enriquece espiritual y materialmente con el disfrute del objeto, sino que, al verse inhabilitado a sacar provecho del mismo, se empobrece cada vez más y cae en la miseria más atroz. "Con la valorización [Verwertung] del mundo cósico crece en directa proporción la desvalorización [Entwertung] del mundo humano" (p. 511).

Como se afirmó más arriba, para ilustrar la inversión del vínculo ideal entre el trabajador y su producción, Marx apela al modelo feuerbachiano de la alienación (Entfremdung) religiosa. De acuerdo con Feuerbach (1969), el hombre se divorcia de sus cualidades más valiosas al atribuírselas a un ser que brota de su propia imaginación. Mientras más pone el ser humano en Dios, menos conserva para sí mismo, más mísero e impotente se vuelve. De modo similar, bajo las condiciones burguesas de producción, "cuanto más objetos produce el trabajador, tanto menos puede poseer y tanto más cae bajo el dominio de su producto [Herrschaft seines Produkts], del capital" (Marx, 1968, p. 512). La objetivación (Vergegenständlichung) del obrero en el producto de su trabajo, que para Marx es una parte esencial en la autoproducción del hombre, se convierte en alienación (Entfremdung). El divorcio del trabajador y sus productos impide que el primero se enriquezca a través del aprovechamiento de los últimos.

Aunque sometiéndolo a modificaciones, Marx conserva hasta el final de su itinerario intelectual el modelo de la alienación religiosa para aludir al vínculo invertido que el ser humano sostiene en la sociedad capitalista con sus propias producciones. De hecho, la concepción del fetichismo de la mercancía, desarrollada en profundidad en el primer capítulo de El capital (Marx, 1932), puede ser pensada como una derivación de este modelo (cfr. Gros, 2013).

\section{Conclusiones}

Con el objetivo de superar las lecturas literales e irreflexivas de los Manuscritos económico-filosóficos de 1844, el presente escrito se propuso poner de manifiesto los leit-motifs hegelianos que informan la concepción positiva del trabajo del joven Marx implícita en el famoso fragmento sobre "el trabajo alienado".

En el primer apartado (1), se intentó reconstruir el abordaje del problema del trabajo que Hegel lleva a cabo en la Fenomenología del espíritu, el texto que más influyó en Marx a la hora de reflexionar sobre la cuestión. Dada la complejidad arquitectónica de esta chef-d'œuvre, resulta imposible comprender el tratamiento del trabajo que allí se encuentra sin antes reconstruir - aunque sea de someramente- la estructura general de la obra. Por esta razón, apelando a las interpretaciones de Dri (2006) y Kojève (2006), se bosquejaron los lineamientos generales de la Fenomenología para determinar el rol que en ella desempeña la problemática del trabajo.

Como se mostró, la concepción hegeliana del trabajo allí bosquejada puede resumirse en dos tesis principales: (a) mediante el trabajo, el hombre logra dominar consciente y voluntariamente la naturaleza tanto "interna" como "externa"; y (b) el trabajo hace posible el desarrollo de la autoconciencia en cuanto que crea un mundo cultural en el que el ser humano puede verse reflejado y reconocerse como tal. 
Por su parte, en el segundo apartado (2), luego de bosquejarse el núcleo filosófico de los Manuscritos económico-filosóficos, se realizó una lectura a contrapelo del fragmento sobre el trabajo alienado orientada a rastrear y desenterrar la concepción positiva del trabajo de Marx. A partir de esta lectura, que tomó como punto de partida la tercera dimensión de la alienación —esto es, la alienación respecto a la esencia genérica humana-, pudo constatarse que, al menos en términos generales, Marx coincide con las dos tesis hegelianas respecto del trabajo humano.

Ahora bien, afirmar esto no implica aseverar que la concepción marxiana del trabajo es un mero derivado de la hegeliana. Por el contrario, como pudo comprobarse, Marx va más allá de Hegel en cuanto que advierte y analiza un rasgo del trabajo humano que este pasa por alto: el carácter negativo que el mismo adquiere bajo las condiciones socioeconómicas del capitalismo, esto es, su alienación o extrañamiento.

\section{Referencias}

Astrada, C. (2003). Hegel y Marx. En C. Astrada y A. Korn, Hegel y Marx (pp. 13-51). Buenos Aires: Quadrata.

Attali, J. (2007). Marx o el espíritu del mundo. Buenos Aires: FCE.

Balibar, É. (2006). La filosofía de Marx. Buenos Aires: Nueva Visión.

Benjamin, W. (1965). Geschichtphilosophische Thesen. En W. Benjamin, Zur Kritik der Gewalt und andere Aufsätze (pp. 78-95). Frankfurt am Main: Suhrkamp.

Blumenberg, W. (1985). Marx. Barcelona: Salvat.

Cornu, A. (1950). Karl Marx und die Entwicklung des modernen Denkens. Berlin: Dietz.

Dal Pra, M. (1971). La dialéctica en Marx. Barcelona: Martínez Roca.

Dri, R. (1994). Razón y libertad. Hermenéutica del capítulo $\checkmark$ de la Fenomenología del espíritu. Buenos Aires: Biblos.

Dri, R. (1999). La odisea de la conciencia moderna. Hermenéutica del capítulo vi de la Fenomenología del espíritu. Buenos Aires: Biblos.

Dri, R. (2001). Dialéctica de la conciencia a la autoconciencia. Razón y revolución, 8.
Dri, R. (2006). Intersubjetividad y reino de la verdad: aproximaciones a la nueva racionalidad. Hermenéutica de los capítulos I-IV. Buenos Aires: Biblos.

D’Hondt, J. (1972). De Hegel a Marx. Buenos Aires: Amorrortu.

Engels, F. (2004). Ludwig Feuerbach und der Ausgang der klassischen deutschen Philosophie. En K. Marx y F. Engels, Studienausgabe Band I. Philosophie [I. Fetscher (ed.)] (pp. 193-236). Berlin: Aufbau.

Fetscher, I. (2004). Marx. Freiburg im Breisgau: Herder.

Feuerbach, L. (1950). Kleine philosophische Schriften. Leipzig: Felix Meiner.

Feuerbach, L. (1969). Das Wesen des Christentums. Stuttgart: Reclam.

Gros, A. E. (2013a). El problema de la socialización en la teoría sociológica general de Heinrich Popitz. Nómadas, 35.

Gros, A. E. (2013b). La crítica de la alienación ante el ocaso de la metafísica. En M. Crespi, M. Lagarrigue y J. Taurel Xifra (Eds.), Marx Manuscrito (pp. 149179). Bahía Blanca: 17grises.

Gros, A. E. (2015). Burocratización y racionalización en Max Weber a la luz de las interpretaciones actuales de su obra. Question, 45, 115-127.

Hegel, G. W. F. (1989). Phänomenologie des Geistes. Frankfurt am Main: Suhrkamp.

Hegel, G. W. F. (1991). Fenomenología del espíritu. México: FCE.

Heidegger, M. (2006). Sein und Zeit. Tübingen: Max Niemeyer.

Honneth, A. (1992). Kampfum Anerkennung. Zur moralischen Grammatik sozialer Konflikte. Frankfurt am Main: Suhrkamp.

Horkheimer, M. (1968). Bemerkungen zur philosophischen Anthropologie. En M. Horkheimer, Kritische Theorie. Band 1 (pp. 220-228). Frankfurt am Main: Fischer.

Husserl, E. (2009). Ideen zu einer reinen Phänomenologie und phänomenologischen Philosophie. Hamburg: Felix Meiner.

Hyppolite, J. (1974). Génesis y estructura de la "Fenomenología del espíritu" de Hegel. Barcelona: Península.

Israel, J. (1977). Teoría de la alienación. Barcelona: Península. 
Kojève, A. (2006). La dialéctica del amo y del esclavo en Hegel. Buenos Aires: Leviatán.

Lapin, N. I. (1974). Der Junge Marx. Berlin: Dietz.

Llanos, A. (1986). Introducción a la dialéctica. Buenos Aires: Rescate.

Löwith, K. (2008). De Hegel a Nietzsche. Buenos Aires: Katz.

Marx, K. (2004). Thesen über Feuerbach. En K. Marx y F. Engels, Studienausgabe Band I. Philosophie [I. Fetscher (ed.)] (pp. 149-152). Berlin: Aufbau.

Marx, K. (1932). Das Kapital. Berlin: Gustav Kiepenheuer.

Marx, K. (1968). Ökonomisch-philosophische Manuskripe aus dem Jahre 1844. En K. Marx y F. Engels. Werke. Band 40 (pp. 467-588). Berlin: Dietz.

Marx, K. (1981a). Zur Judenfrage. En K. Marx y F. Engels, Werke, Band 1 (pp. 347-388). Berlin: Dietz.

Marx, K. (1981b). Zur Kritik der Hegelschen Rechtsphilosophie. En K. Marx y F. Engels, Werke, Band 1 (pp. 378-391). Berlin: Dietz.
Marx, K. y Engels. F. (2004). Vorrede [zu Feuerbach. 1. Teil der ,Deutschen Ideologie']. En K. Marx y F. Engels, Studienausgabe Band I. Philosophie [I. Fetscher (ed.)] (pp. 89-149). Berlin: Aufbau.

Popitz, H. (1967). Der entfremdete Mensch. Zeitkritik und Geschichtsphilosophie des jungen Marx. Frankfurt am Main: Europäische Verlaganstalt.

Popitz, H. (2009). Phänomene der Macht. Tübingen: Mohr Siebeck.

Sayers, S. (2011). Marx and Alienation. Essays on Hegelian Themes. London: Palgrave Macmillan.

Skempton, S. (2010). Alienation after Derrida. New York: Continuum International Publishing Group.

Weber, M. (1988). La ética protestante y el "espíritu" del capitalismo. Barcelona: Península. 